\title{
Research on the Evaluation and Performance of Regional Tourism Industrial Agglomeration
}

\author{
Ting-Min KE \\ Wenzhou vocational \& technical college, Wenzhou, 810008, China \\ 506306982@qq.com
}

Keywords: Evaluation and performance, Regional tourism, Industrial agglomeration.

\begin{abstract}
With the development of China's tourism economy, the tourism industry has gradually become a new growth point of national economy and promotes the development of the third industry an important focal point. At present, the 30 provinces, autonomous regions and municipalities of China respectively positioned the pillar industry; leading industry, leading industry and leading industry according to their own situation to the tourism industry of directly under the central government to carry out a large number of tourism planning, formulate supporting policies, effectively promoted the development and prosperity of tourism industry.
\end{abstract}

\section{Introduction}

There are still to be standardized and improved in China's tourism industry vigorous development in the future, mainly in the following three aspects: firstly, the tourism industry is small (small scale, enterprise group, less joint operations less), powder (decentralized management, target market fragmentation, the pertinence is not strong), weak (not abundant, capital resources, weak competitive ability difference (difference), operation management, poor quality of services, poor economic returns) to highlight the contradictions, seriously affected the tourism enterprise economic benefit and social benefit to be improved. Secondly, the convergence of regional tourism industrial structure. Its rigid structure tourism industry and its changes in the market understanding of the hysteresis makes its supply adjusting rhythm slow, difficult to identify the key changes in the market, leading to low level repeated construction, the excess supply of similar products. Once again, the regional tourism industry competition. Provincial, city, and district government have invested a large amount of labor, the funds to strengthen its tourism image and attractive, even the introduction of measures to a variety of preferential policies to stimulate the development of tourism investment, resulting in some provinces tourism beyond the region's economic and social capacity, resulting in the development of tourism resources destruction and regional industrial structure of maladjusted and catastrophic the consequences.

Industrial agglomeration is the inevitable result of the development of regional economy, and an important driving force to promote regional economic development. In recent years, regional tourism industry agglomeration has become the focus of attention of the industry; the research on the problem of regional tourism industrial agglomeration has increasingly become an important content of tourism research. At present, China's tourism industry has shown a trend of convergence to a certain extent, such as the Pearl River Delta, Yangtze River Delta and Beijing Tianjin Hebei area, these areas are largely achieved configuration and tourism economy of scale optimization of tourism resources, to avoid redundant construction and vicious competition. Therefore, in order to solve all kinds of problems existing in the development of regional tourism industry in our country, industrial cluster is one of the most important ways.

Agglomeration of regional tourism industry to produce a certain performance, the correct understanding of cluster performance contributes to a more reasonable formulate corresponding tourism development strategy and planning for the tourism development, and then promote the development of regional tourism industry. Although China has formed a little agglomeration development significantly, with strong competitiveness, brand effect is very obvious big tourism 
cluster, but how to correct this problem of regional tourism industry cluster and its performance evaluation has not yet been solved. The study on the industry cluster theory as a guide, in East China six provinces and one city as an example, the objective of regional tourism industry agglomeration level of cluster and the performance evaluation, and puts forward the corresponding policy recommendations, the hope can provide reference and experience for the development of regional tourism industry cluster of China.

\section{Research significance}

\section{Theoretical significance}

Generally speaking, performance evaluation is mostly used in the enterprise level, regional and industry as the foothold in the study is less, the study on regional tourism industry cluster performance evaluation has the certain innovation. Secondly, the research expanded of the research from the perspective of industry performance. Theoretical and empirical researches on the industry performance, are mostly concentrated in the manufacturing and new and high technology, less used in the tourism industry in the service industry. Therefore, to evaluate the performance of the tourism industry, the more extended the research from the perspective of industry performance. Third, enrich and improve the tourism industry cluster research content. This paper first analyzed the agglomeration level of regional tourism industry, on the basis of previous research, revise and improve the regional tourism industry cluster performance evaluation index system, in-depth analysis of the use of information entropy weight TOPSIS method, so as to achieve the objective, comprehensive evaluation of regional tourism industrial cluster performance, enrich the research present different scholar in the field of content, to promote the study of regional tourism research and tourism economics to constantly enrich and develop the constructive significance.

\section{Practical significance}

The emergence of a large number of agglomeration is intensive, innovative development of the tourism industry has opened up a path, however, the excessive concentration of the tourism industry has also brought a lot of problems. In spite of some areas of their own conditions, the disorder of excessive development, overload operation, so that the rapid deterioration of the ecological environment, tourism development of flower briefly as the broad-leaved epiphyllum. Therefore, the use of regional tourism industrial cluster performance evaluation index system of tourism industry, a city in East China six province cluster performance an empirical study, in order to correct understanding and evaluation of cluster performance, the significance of sustainable development of regional tourism industry major. Moreover, the current China's tourism industry, repeated construction, vicious competition phenomenon is serious, it is difficult to obtain scale economy. In this paper, through the research on cluster performance, to investigate the effect of industrial economy of scale, to extend the industrial chain of tourism industry and tourism play radiation impetus function, providing a theoretical basis and practical guidance for the government to formulate the policies of tourism industry, tourism industry so as to find the performance improvement path, to solve the problem of scale economy of China's tourism industry, the tourism industry development of science.

\section{Research reviews}

Usually in the tourist attraction is the core of regional tourism industry cluster, to obtain economies of scale, according to build up a professional division of labor and cooperation demand of formal and informal relationships and the formation of tourism related enterprises gathered in a particular region. Regional tourism industry cluster performance research is based on the regional economics in late nineteenth Century as the foundation, with the aid of industrial economics, development economics, economic geography and other academic achievements, and gradually developed. Field of studies are as follows: 


\section{Agglomeration of the industry}

Marshall (1890) first proposed the industrial agglomeration and the internal and external economic aggregation space (External Economies) concept, and elaborated the existence of external economy and economy of scale (Scale Economies) under the condition of economic motivation of industrial agglomeration resulting. Porter (1991) thinks that the industrial cluster members through reducing the production cost and information cost, have higher opportunity cost, and to improve productivity and wages. Paul R. Krugman (2000) concentration of industries from the general point of view, further explained in the different style of increasing return to scale (Increasing Returns) and different types of transportation cost (Mobility Cost) the trade-off problem between.

With the development of tourism industry agglomeration phenomenon gradually being cognitive, industrial cluster and the cluster theory is increasingly being applied to the study of the regional tourism industry. Jackson (2006) argues that regional agglomeration can enhance the competitiveness of the tourism industry, characteristic tourism industry clusters in the enterprise can better understand competition, and with the development of cooperation competition behavior consistent with industry cluster. Fan Jianyong (2006) from the industrial agglomeration, labor productivity, the gap between regions is linked closely to each other of the non-agricultural industry, that is the source of increasing returns to scale local industry cluster. Lu Yi (2010) analyzed data research report 1998-2005 of China in manufacturing industry, confirmed the positive relationship between industrial cluster and enterprise scale.

\section{Tourism Industrial Agglomeration}

With the development of tourism industry agglomeration phenomenon gradually being cognitive, industrial cluster and the cluster theory is increasingly being applied to the study of the regional tourism industry. Jackson (2006) argues that regional agglomeration can enhance the competitiveness of the tourism industry, characteristic tourism industry clusters in the enterprise can better understand competition, and with the development of cooperation competition behavior consistent with industry cluster. Yuhei Inoue (2011) thinks that social responsibility will impact to the tourism industry's economic performance, thus restricting the tourism industry agglomeration. Guo Wei and He Yuanyuan (2008), sub Regional Panel Data of 1992-2005 years of tourism industry cluster, convergence and employment on the basis of the differences are discussed. Lu Yi (2010) analyzed data research report 1998-2005 China in manufacturing industry, confirmed the positive relationship between industrial cluster and enterprise scale. Wang Kai and Yi Jing (2013) with Gini coefficient and industry area concentration of industrial agglomeration index and industry profit rate, coefficient of employment, labor productivity industry performance indicators, based on the data of 2010 section, an exploration of the relationship between industry agglomeration Chinese tourism industry and between industry performance.

\section{Case study}

Wang Zhongcheng and Li Jinlian (2006) based on evaluating the status quo of agglomeration of tourism industry in Yangtze River Delta, analyzed the agglomeration and the contents of the tourism industrial cluster strategy advancing tourism industry departments. Pelin Arsezen-Otamisa and Nedim Yuzbasioglu (2013) in Turkey of Antalya tourism industry cluster performance research, choosing 2020 Sample, based on the model and the diamond structure equation model, the influence factors on the perceived performance of the tourism industry cluster analysis. The results of this study show the characteristics of Antalya tourism industry cluster, industrial network and clusters can promote tourism industrial cluster performance improvement.

\section{Research review}

On the international tourism industry agglomeration attention earlier, related research is mainly the use of regional industrial cluster theory and quantitative analysis method of regional tourism industry agglomeration and its performance problems, to explore the relationship and focus on the economic impact of tourism industry agglomeration on regional development and tourism 
enterprises competitiveness. Relatively speaking, the research on tourism industry cluster started late, at present mainly in the tourism industry agglomeration spatial phenomenon, nature, causes and effects of the mechanism and other aspects of the research and achieved certain results. However, so far, the research on performance of tourism industry agglomeration mostly adopts the static analysis, the evaluation index system of model construction too much emphasis on the space dimension, time dimension while ignoring the dynamic research is rare, may affect the regional (Tourism) industrial policy to develop the science of. In view of this, this project researches of domestic and abroad, on the basis of previous studies, the construction of cluster performance model, and on the basis of previous research, we modify the index system perfect, in East China six provinces and one city as the object, the regional tourism industry agglomeration and its performance of quantitative research and comparative analysis, and puts forward relevant policy suggestions, develop tourism industry development policy in order to provide the theory.

\section{Research methods}

1, Induction and deduction method: according to the related literature on the research of tourism industry agglomeration and its performance at home and abroad, analysis, induction and evaluation.

2, Qualitative and quantitative analysis: on the basis of qualitative analysis, build the performance model of agglomeration of regional tourism industry, revise and improve the evaluation index system, the evaluation of its performance using information entropy weight TOPSIS method, and proposes the policy suggestion.

3, Empirical analysis: a city of East China area six tourism industry agglomeration performance empirical study.

4, Interdisciplinary research methods: the related theory and method of the comprehensive use of tourism, statistics and economics, focuses on the analysis of regional tourism industry cluster performance problems.

\section{Research contents}

\section{Analysis of regional tourism industry agglomeration level}

In many qualitative, quantitative evaluation index of tourism industry agglomeration of agglomeration level of recognition, location quotient to geographical space from multi angle measuring regional tourism industry development, reflect the concentration characteristics of spatial regional tourism industry overall, spatial Gini coefficient reflects the tourism industry spatial unbalance degree, therefore, this study uses location quotient and space the Gini coefficient to measure the tourism industrial agglomeration degree.

\section{The performance evaluation of the regional tourism industry agglomeration}

Clustering evaluation is a kind of comprehensive judgment business activities process and results of the regional tourism industry cluster in a certain period of time to make such judgments, and provides a basis for the development of agglomeration.

The construction of model. The operation mechanism of regional tourism industrial agglomeration, tourism industry is the absorption of human, material and financial resources, from the surrounding environment, information and other resources input cluster internal, specialized division of labor, competition and cooperation, innovation process through agglomeration organization play a gathering effect, the output of products, services, knowledge, technology, talents, and agglomeration on regional the economy through tourism industry, including the driving effects on regional economy, the radiation effect and demonstration effect, promote the development of regional economy. Therefore, the regional tourism industrial cluster performance, including at least two aspects, one, the generating process of regional tourism industrial agglomeration results, namely, resource input, including tourism resources, infrastructure, supply, and industrial agglomeration of specialized division of labor, cooperation competition, innovation behavior; secondly, result of industrial agglomeration industrial agglomeration, namely the output products, 
services, knowledge, technology, talents, the effect of promoting regional economic development, this effect can be summarized as the tourism industrial agglomeration itself outputs, namely, the effect of scale economy, and the promotion of the regional economy, namely the economy promotion ability.

Construction of index system. According to the performance model of regional tourism industry agglomeration of agglomeration above, the performance evaluation mainly focus on the degree of specialization, competition and cooperation, the degree of innovation, tourism resources, service infrastructure, economic scale effect and economy promotion seven aspects ability, constructing the regional tourism industry agglomeration index of performance evaluation is to subdivide these index. According to the principle of the index system, and refer to the relevant literature, combined with the actual situation of the development of the tourism industry is modified, determine the index system of regional tourism industry agglomeration performance evaluation, mainly divided into the target layer, criterion layer and index layer three levels. The target layer is the regional tourism industrial cluster performance comprehensive evaluation; criteria layer includes "professional degree", "Competition" degree, "the degree of innovation", "tourism resources", "service infrastructure", "economies of scale" and "economic ability to promote" 7 first level indicators, including indicators layer "the total income of tourism location quotient" and 32 two level indexes.

The index system optimization. The index system is optimized through the index information area test, index of correlation degree test, to get the final evaluation index system.

Comprehensive evaluation. For the comprehensive evaluation of the tourism industry in East China area cluster performance using information entropy TOPSIS method, and put forward the corresponding policy recommendations, in order to promote the sustainable development of regional tourism industry.

\section{References}

[1] Huang J.H, Min J.C.H. 2002, Earthquake devastation and recovery in tourism: The Taiwan case.Tourism Management,23:145-154.

[2] Kevin G., and Wendell M., 2000, The impact of regulatory measures on commercial bank interest rates: A micro analysis of the Barbados case. International Advances in Economic Research, 6:544-556.

[3] Nuri Ucara. 2009, Tolga Omayc. Testing for unit root in nonlinear heterogeneous panels. Tourism Science,104:6-9.

[4] S. Makridakis, 1986, Forecasting when pattern changes occur beyond the historical data, Management Science, 32:257-271.

[5] Smeral E., Wuger M. 2005, Does complexity matter? Methods for improving forecasting accuracy in tourism:The case ofAustralia. Journal of Travel Research, 44:100-110.

[6] Tideswell C., Mules T., Faulkner B. 2001, An integrative approach to tourism forecasting:A glance in the rereview mirror. Journal of Travel Research, 40:162-171.

[7] Y. P. Li. 2000, Geographical Consciousness and Tourism Experience. Annals of Tourism Research, 27:863-883. 